\title{
Pemanfaatan Ekstrak Daun Tembakau sebagai Inhibitor Korosi pada Logam Baja Karbon dan Aluminium
}

\author{
Adhi Setiawan*), Novi Eka Mayangsari, Denny Dermawan \\ Prodi Teknik Pengolahan Limbah, Jurusan Teknik Permesinan Kapal, Politeknik Perkapalan \\ Negeri Surabaya (PPNS) \\ *email: adhistw23@gmail.com
}

Received: 20/11/2018; Revised: 26/12/2018; Accepted: 27/12/2018

\begin{abstract}
Abstrak
Ekstrak daun tembakau dapat dimanfaatkan sebagai inhibitor korosi pada logam baja karbon dan aluminum di dalam larutan $\mathrm{HCl}$. Penelitian ini bertujuan menganalisis pengaruh konsentrasi ekstrak daun tembakau terhadap laju korosi serta efisiensi inhibisi korosi logam baja karbon dan aluminium di dalam media larutan $\mathrm{HCl}$ 0,1 M. Laju korosi logam baja karbon dan aluminium dianalisis menggunakan metode polarisasi linear. Hasil penelitian menunjukkan bahwa peningkatan konsentrasi ekstrak daun tembakau dapat menurunkan laju korosi pada logam baja karbon dan aluminium. Laju korosi minimum baja karbon dan aluminium terjadi pada konsentrasi inhibitor sebesar $700 \mathrm{mg} / \mathrm{L}$ yaitu masing-masing sebesar $0,940 \mathrm{~mm} / \mathrm{y}$ dan $0,807 \mathrm{~mm} / \mathrm{y}$. Peningkatan konsentrasi inhibitor menyebabkan peningkatan efisiensi inhibisi korosi baja karbon dan aluminium. Hasil SEM menunjukkan bahwa peningkatan konsentrasi inhibitor menyebabkan proteksi korosi semakin tinggi sehingga tingkat degradasi permukaan logam akibat korosi semakin rendah.
\end{abstract}

Kata kunci: ekstrak daun tembakau, inhibitor, korosi, polarisasi linear

\begin{abstract}
Tobacco leaf extract can be used as a corrosion inhibitor in carbon steel and aluminum metals in $\mathrm{HCl}$ solutions. This study aims to analyze the effect of the concentration of tobacco leaf extract on the corrosion rate and the inhibition efficiency of corrosion of carbon steel and aluminum metal in the $\mathrm{HCl}$ $0.1 \mathrm{M}$. The corrosion rate of carbon steel metal and aluminum was analyzed using the linear polarization method. The results showed that an increase in the concentration of tobacco leaf extract could reduce the corrosion rate in carbon steel and aluminum metals. The minimum corrosion rate of carbon steel and aluminum occurred at the inhibitor concentration of $700 \mathrm{mg} / \mathrm{L}$ occurred at the inhibitor concentration of 700 that is $0.940 \mathrm{~mm} / \mathrm{y}$ and $0.807 \mathrm{~mm} / \mathrm{y}$ respectively. Increased inhibitor concentration caused increase in the inhibition efficiency of carbon steel and aluminum. SEM results indicate that the increase in inhibitor concentration causes higher corrosion protection so that the level of degradation of metal surfaces due to corrosion is lower.
\end{abstract}

Keywords: corrosion, inhibitor, linear polarization, tobacco leaf extract

\section{PENDAHULUAN}

Korosi merupakan proses degradasi dari material logam yang disebabkan oleh reaksi elektrokimia logam dengan lingkungannya. Proses korosi menyebabkan penurunan sifat mekanik logam sehingga dapat menyebabkan kerugian dalam aspek ekonomi dan keselamatan (Li et al., 2016; Setiawan et al., 2017). Korosi merupakan masalah yang dihadapi hampir di seluruh negara di dunia karena diperkirakan sekitar 1\%-5\% 
dari produk nasional bruto (GNP) hilang karena korosi. Pada tahun 1998 The National Association of Corrosion Engineers (NACE) mencatat bahwa biaya total tahunan dari korosi mencapai di Amerika Serikat mencapai 276 milyar dollar atau sekitar 3,1 dari GNP (Verma et al., 2017).

Korosi menghasilkan degradasi yang menyebabkan terjadinya kegagalan pada sistem industri proses serta manufaktur. Pengendalian korosi logam di industri memerlukan biaya yang relatif tinggi (Bhaskaran et al., 2005). Kerusakan logam akibat korosi dapat dicegah melalui beberapa metode yaitu pemilihan material, pelapisan, proteksi katodik, serta penggunaan inhibitor korosi (Al-Otaibi et al., 2014; Setiawan et al., 2017). Penggunaan inhibitor korosi merupakan metode terbaik dalam mencegah kerusakan atau degradasi permukaan logam dari media yang korosif (De-Souza dan Spinelli, 2009). Pengendalian korosi logam dengan menggunakan inhibitor merupakan metode yang relatif ekonomis serta praktis dalam mengurangi serangan korosi pada logam. Inhibitor korosi pada umumnya berupa senyawa kimia sintetik atau alami yang ditambahkan di dalam media korosif pada konsentrasi yang relatif rendah dengan tujuan menurunkan laju korosi logam akibat pengaruh lingkungan (Qiang et al., 2018; Setiawan et al., 2017).

Beberapa senyawa sintetik terbukti cukup efektif sebagai inhibitor korosi logam. Namun, penggunaan inhibitor korosi sintetik saat ini cukup terbatas karena peraturan lingkungan yang ketat serta bersifat racun sehingga berbahaya bagi kehidupan manusia dan hewan. Oleh karena itu, diperlukan penelitian dalam pengembangan inhibitor korosi yang ramah lingkungan, biodegradable, murah, tidak beracun, serta memiliki efisiensi yang baik (Mehdipour et al., 2015).

Ekstrak tanaman merupakan produk alami yang bersifat dapat diperbaharui, murah, tidak beracun, serta jumlahnya melimpah. Kandungan kimia dari ekstrak tanaman seperti flavonoid, polifenol, dan polisakarida berpotensi menghambat korosi pada logam (Liao et al., 2018). Ekstrak daun, biji, bunga, serta akar dari tanaman dapat digunakan menurunkan laju korosi logam pada lingkungan yang berbeda (Chebouat et al., 2013). Berbagai macam dari ekstrak tanaman telah dimanfaatkan sebagai inhibitor korosi pada logam baja dengan cukup efektif antara lain yaitu ekstrak kulit jeruk, bamboo, Nigella sativa, daun ginkgo, buah lychee (Liao et al., 2018; Qiang et al., 2018). Hasil penelitian menunjukkan bahwa ekstrak tanaman tersebut mengandung senyawa organik kompleks seperti tannin, alkaloid, flavonoid, dan basa nitrogen. Senyawa organik tersebut memilki kandungan heteroatom (, S, dan $\mathrm{O}$ ), gugus elektronegatif, serta ikatan rangkap konjugasi sebagai pusat adsorpsi utama dari inhibitor korosi (Yaro et al., 2013).

Berbagai penelitian saat ini telah banyak melaporkan tentang efektifitas inhibitor korosi yang disintesis dari ekstrak tanaman terhadap laju korosi logam. Qiang et al. (2018) mempelajari pengaruh ekstrak daun Ginkgo sebagai inhibitor pada logam baja X70 di dalam media korosif larutan HCl. Odewunmi et al. (2015) melakukan studi pemanfaatan ekstrak kulit semangka sebagai inhibitor korosi baja karbon di dalam media larutan $\mathrm{H}_{2} \mathrm{SO}_{4}$ dan $\mathrm{HCl}$. Kandungan citruline yang tersusun atas struktur heteroatom $(\mathrm{N}, \mathrm{O})$ serta gugus aromatik sebagai pusat adsorpsi sehingga 
ekstrak kulit semangka berpotensi sebagai inhibitor korosi logam. Chaubey et al. (2016) melakukan studi pengaruh penambahan ekstrak kulit pepaya sebagai inhibitor korosi logam aluminium pada larutan $\mathrm{HCl} 1 \mathrm{M}$ dengan pendekatan secara elektrokimia dan quantum chemicals. M'hiri et al. (2016) melaporkan bahwa ekstrak kulit jeruk memiliki kandungan antioksidan (asam askorbat, naringin, serta neohesperidin) yang dapat menghambat korosi baja karbon di dalam lingkungan asam melalui pembentukan lapisan presipitasi yang menutup permukaan logam. Beberapa penelitian sebelumnya lebih banyak mempelajari tentang pengaruh ekstrak bagian buah tanaman sebagai inhibitor korosi. Beberapa bagian tanaman seperti daun tembakau, daun jambu biji, serta daun teh mengandung alkaloid yang dapat dimanfaatkan sebagai inhibitor korosi (Yanuar et al., 2016)

Tembakau merupakan jenis tanaman yang banyak dibudidayakan di dunia sebagai bahan baku rokok. Daun tembakau memiliki kandungan asam organik, komponen fenol, dan senyawa alkaloid yang berpotensi sebagai inhibitor korosi logam (Bhawsar et al., 2015). Namun, pemanfaatan daun tembakau saat ini masih terbatas sebagai bahan baku rokok. Produksi daun tembakau indonesia pada tahun 2010 diperkirakan mencapai 182 ribu ton sehingga cukup berpotensi untuk dikembangkan menjadi produk inhibitor korosi yang ramah lingkungan (Paramartha et al., 2013). Yanuar et al. (2016) dalam penelitiannya melaporkan bahwa ekstrak daun tembakau dapat menurunkan laju korosi baja A53 pada lingkungan air laut buatan dengan kadar $\mathrm{NaCl} 3,5 \%$. Hasil penelitian tersebut diperoleh efisiensi inhibisi korosi sebesar 30,43\%. Ahmadi et al. (2016) melaporkan bahwa penambahan 60 ppm ekstrak daun tembakau dapat memberikan efisiensi inhibisi korosi sebesar 80,94\% pada baja API 5L X-52 di dalam air laut buatan dengan kadar $\mathrm{NaCl}$ $2 \%$. Beberapa penelitian sebelumnya yang menggunakan ekstrak daun tembakau sebagai inhibitor korosi logam belum menjelaskan secara detail mekanisme proses inhibisi korosi. Bahkan, informasi tentang kandungan bahan aktif yang berperan sebagai inhibitor pada ekstrak daun tembakau belum diidentifikasi secara jelas. Selain itu, karakteristik inhibisi ekstrak daun tembakau terhadap laju korosi baja karbon dan aluminium di dalam larutan $\mathrm{HCl}$ pada konsentrasi rendah belum banyak diinvestigasi pada penelitian sebelumnya.

Penelitian ini bertujuan untuk mempelajari pengaruh konsentrasi ekstrak daun tembakau terhadap laju korosi serta efisiensi inhibisi korosi logam baja karbon dan aluminium di dalam larutan $\mathrm{HCl} 0,1$ M. Identifikasi kandungan senyawa kimia di dalam ekstrak daun tembakau menggunakan metode GC-MS serta analisis laju korosi logam tersebut menggunakan metode polarisasi linear.

\section{METODE PENELITIAN}

Bahan baku yang digunakan pada penelitian ini antara lain daun tembakau kering yang dibeli dari pasar tradisional, aquadest, larutan $\mathrm{HCl} 37 \%$ pro-analysis (Merck), larutan etanol 96\% (SAP), kertas saring, logam aluminium, dan baja karbon. Peralatan yang digunakan dalam ekstraksi daun tembakau terdiri dari labu leher tiga $300 \mathrm{ml}$, kondensor refluks, termometer dan pemanas.

Proses ekstraksi dilakukan dengan mencampurkan $20 \mathrm{~g}$ daun tembakau kering 
bersama dengan $200 \mathrm{ml}$ aquadest di dalam labu leher tiga. Proses ekstraksi dilakukan pada suhu $100{ }^{\circ} \mathrm{C}$ selama 2 jam. Ekstrak selanjutnya didinginkan sampai dengan suhu ruang dan disaring untuk memisahkan antara larutan ekstrak dengan residunya. Residu sisa hasil ekstraksi selanjutnya dikeringkan di dalam oven pada suhu $60^{\circ} \mathrm{C}$ selama 3 jam. Konsentrasi ekstrak tembakau dapat dihitung berdasarkan selisih berat tembakau sebelum dan sesudah ekstraksi.

Analisis kandungan kimia dari ekstrak daun tembakau dilakukan dengan menggunakan Gas Chromatography-Mass Spectrometry (Agilent 6980N). Volume injeksi sampel yang digunakan sebesar 2 $\mu \mathrm{L}$ dengan split $1 / 10$ pada suhu injektor $290^{\circ} \mathrm{C}$. Oven GC-MS diprogram pada suhu $50^{\circ} \mathrm{C}$ (ditahan selama 5 menit) dilanjutkan kenaikan suhu sampai dengan $280^{\circ} \mathrm{C}$ (ditahan selama 15 menit) dengan laju pemanasan sebesar $10^{\circ} \mathrm{C} /$ menit.

Analisis gugus fungsi yang terkandung di dalam ekstrak daun tembakau menggunakan Fourier Transform Infrared (FT-IR) (Thermo Scientific Nicolet iS10) pada panjang gelombang $4000-400 \mathrm{~cm}^{-1}$.

Pengujian laju korosi logam dilakukan dengan menggunakan metode polarisasi linear (PGSTAT 302N Autolab Metrohm) yang dilakukan pada suhu ruangan. Dimensi plat logam yang digunakan pada pengujian korosi yaitu sebesar $15 \mathrm{~mm}$ x $10 \mathrm{~mm}$ x $1 \mathrm{~mm}$. Pembersihan kotoran pada permukaan logam sebelum pengujian korosi dilakukan menggunakan kertas gosok grit 350 serta dilanjutkan dengan pembilasan menggunakan larutan etanol. Logam uji selanjutnya di keringkan ke dalam oven pada suhu $60^{\circ} \mathrm{C}$ selama 30 menit.
Elektroda pada pengujian korosi secara elektrokimia menggunakan tiga elekroda yang terdiri dari elektoda kerja berupa logam baja karbon atau aluminium, elektroda counter berupa platina dan elektroda referensi menggunakan $\mathrm{Ag} / \mathrm{AgCl}$. Logam uji tersebut selanjutnya dicelupkan ke dalam larutan $\mathrm{HCl} 0,1 \mathrm{M}$ yang mengandung ekstrak daun tembakau sebesar 0 (blank), 100, 300, 500, dan 700 $\mathrm{mg} / \mathrm{L}$. Potensial scan pada polarisasi linear dilakukan pada interval $-300 \mathrm{mV}$ sampai dengan $300 \mathrm{mV}$ terhadap Open Circuit Potential (OCP). Ekstrapolasi grafik Tafel hasil polarisasi linear dilakukan dengan Software Nova untuk memperoleh parameter Icorr dan Ecorr. Laju korosi logam selanjutnya dapat dihitung dengan Persamaan (1).

$$
C R(\mathrm{~mm} / \mathrm{y})=\frac{3,27 \cdot 10^{-3} i_{\text {corr }} E W}{D}
$$

Dengan CR merupakan laju korosi. icorr adalah rapat arus korosi $\left(\mu \mathrm{A} / \mathrm{cm}^{2}\right)$. EW merupakan berat ekivalen logam. D merupakan densitas logam $\left(\mathrm{g} / \mathrm{cm}^{3}\right)$. Besarnya efisiensi inhibisi dan surface coverage $(\theta)$ ekstrak daun tembakau dihitung dengan Persamaaan (2) dan (3).

$$
\begin{aligned}
& E I(\%)=\frac{C R_{\text {uninhibital }}-C R_{\text {inhibited }}}{C R_{\text {uninhibital }}} \times 100 \% \\
& \theta=\frac{C R_{\text {uninhibital }}-C R_{\text {inhibited }}}{C R_{\text {uninhibital }}}
\end{aligned}
$$

$\mathrm{CR}_{\text {unihibited }}$ dan $\mathrm{CR}_{\text {inhibited }}$ masing-masing merupakan laju korosi logam tanpa dan dengan menggunakan inhibitor. Selanjutnya, morfologi permukaan logam yang terkontak dengan larutan $\mathrm{HCl}$ tanpa atau dengan inhibitor dianalisis dengan menggunakan metode Scanning Electron Microscope (Inspect S50) yang dioperasikan pada $20 \mathrm{kV}$. 


\section{HASIL DAN PEMBAHASAN}

Proses inhibisi korosi logam baja karbon dan aluminium dapat dianalisis berdasarkan metode elektrokimia menggunakan polarisasi linear. Gambar 1 menunjukkan kurva polarisasi logam baja karbon dan aluminium di dalam larutan $\mathrm{HCl}$ pada berbagai variasi konsentrasi ekstrak daun tembakau. Parameter elektrokimia dari analisis polarisasi linear disajikan pada Tabel 1. Hasil penelitian menunjukkan bahwa penambahan ekstrak daun tembakau di dalam larutan $\mathrm{HCl}$ dapat menurunkan laju korosi logam baja karbon dan aluminium. Semakin tinggi konsentrasi ekstrak daun tembakau di dalam larutan $\mathrm{HCl}$ 0,1 M maka laju korosi kedua logam tersebut semakin rendah. Laju korosi minimum pada logam baja karbon dan aluminium terjadi pada konsentrasi inhibitor sebesar $700 \mathrm{mg} / \mathrm{L}$ dengan nilai sebesar $0,940 \mathrm{~mm} / \mathrm{y}$ dan $0,807 \mathrm{~mm} / \mathrm{y}$.

Hasil penelitian menunjukkan bahwa peningkatan konsentrasi inhibitor ekstrak daun tembakau dapat menurunkan arus korosi logam yang menyebabkan efisiensi inhibitor semakin tinggi. Efisiensi inhibisi korosi logam baja karbon dan aluminium terjadi pada konsentrasi inhibitor sebesar $700 \mathrm{mg} / \mathrm{L}$ dengan nilai efisiensi inhibisi masing-masing mencapai $71,71 \%$ dan $72,44 \%$. Hasil perhitungan surface covered oleh inhibitor yang menunjukkan bahwa peningkatan konsentrasi inhibitor ekstrak daun menyebabkan penurunan laju korosi untuk kedua jenis logam akibat adsorpsi inhibitor pada permukaan logam yang menutup permukaan logam sehingga menghambat perpindahan elektron pada korosi. Hasil penelitian tentang penggunakan ekstrak tanaman sebagai inhibitor korosi juga telah dilaporkan oleh beberapa penelitian sebelumnya. Mourya et al. (2014) melaporkan bahwa penggunaan ekstrak tanaman Tagetes erecta pada konsentrasi $1000 \mathrm{mg} / \mathrm{L}$ di dalam media $\mathrm{H}_{2} \mathrm{SO}_{4} \quad 0,5 \quad \mathrm{M}$ dapat memberikan efisiensi inhibisi korosi baja sebesar 40\%. Al-Turkustani (2010) menggunakan ekstrak lidah buaya sebagai inhibitor korosi logam aluminium di dalam media $\mathrm{HCl} 0,5 \mathrm{M}$. hasil penelitian menunjukkan bahwa penambahan ekstrak lidah buaya sebesar $48 \mathrm{v} / \mathrm{v}$ mampu memberikan efisiensi inhibisi sebesar 70,34\%.

Berdasarkan hasil penelitian yang diperoleh serta perbandingan dengan beberapa penelitian sebelumnya menunjukkan bahwa ekstrak tanaman tembakau terbukti efektif dalam menghambat korosi pada baja karbon di dalam larutan $\mathrm{HCl}$ pada konsentrasi yang rendah. Penurunan arus korosi akibat penambahan inhibitor disebabkan oleh adsorpsi inhibitor pada permukaan baja karbon dan aluminium yang membentuk film proteksi yang menghambat difusi elektron dari atau menuju permukaan elektroda sehingga proses korosi dapat dihambat (Odewunmi et al., 2015).

Hasil analisis ekstrapolasi kurva polarisasi linear menunjukkan bahwa peningkatan konsentrasi inhibitor pada larutan $\mathrm{HCl} 0,1 \mathrm{M}$ cenderung menggeser nilai Ecorr baja dan aluminium menjadi lebih positif bila dibandingkan dengan larutan tanpa inhibitor. Hal tersebut mengindikasikan bahwa inhibitor yang dibuat dari ekstrak daun tembakau dapat dikatagorikan sebagai mixed inhibitor (Hegazy et al., 2018). 
Pemanfaatan Ekstrak Daun Tembakau sebagai Inhibitor Korosi pada Logam Baja Karbon dan Aluminium
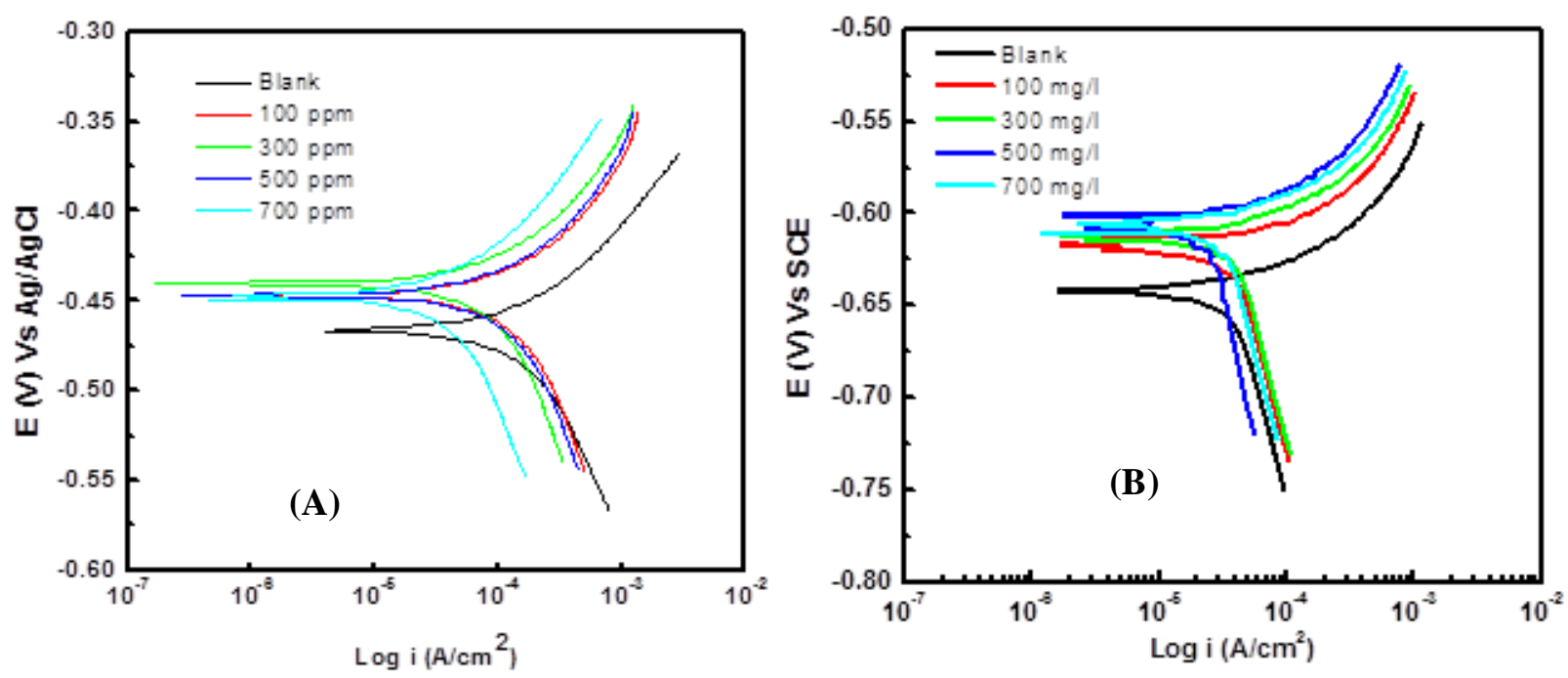

Gambar 1. Grafik Polarisasi Linear Logam di Dalam Larutan $\mathrm{HCl}$ 0,1 M (a) Baja Karbon (b) Aluminium

Tabel 1. Parameter Polarisasi Linear Baja Karbon dan Aluminium di Dalam HCl 0,1 M

\begin{tabular}{lllllll}
\hline Logam & $\begin{array}{l}\text { Konsentrasi } \\
(\mathbf{m g} / \mathbf{L})\end{array}$ & Ecorr $(\mathbf{m V})$ & $\begin{array}{l}\text { Icorr } \\
\left(\boldsymbol{\mu A} / \mathbf{c m}^{2}\right)\end{array}$ & IE $(\boldsymbol{\%})$ & $\begin{array}{l}\mathbf{C R} \\
(\mathbf{m m} / \mathbf{y})\end{array}$ & $\boldsymbol{\theta}$ \\
\hline \multirow{3}{*}{ Baja } & Blank & $-466,18$ & 285,03 & - & 3,31 & - \\
Karbon & 100 & $-446,51$ & 206,19 & 27,84 & 2,39 & 0,28 \\
& 300 & $-428,65$ & 156,62 & 45,35 & 1,81 & 0,45 \\
& 500 & $-440,34$ & 145,19 & 49,28 & 1,68 & 0,49 \\
& 700 & $-447,22$ & 80,76 & 71,71 & 0,93 & 0,71 \\
\hline \multirow{4}{*}{ Aluminium } & Blank & $-641,90$ & 268,54 & - & 2,93 & - \\
& 100 & $-618,30$ & 172,33 & 35,83 & 1,88 & 0,36 \\
& 300 & $-611,99$ & 154,08 & 42,62 & 1,68 & 0,43 \\
& 500 & $-607,86$ & 99,93 & 62,80 & 1,10 & 0,63 \\
& 700 & $-606,04$ & 74,02 & 72,44 & 0,81 & 0,72 \\
\hline
\end{tabular}

Gambar 2. menunjukkan hasil analisis dari kandungan kimia ekstrak daun tembakau. Hasil analisis GC-MS menunjukkan bahwa ekstrak daun tembakau memiliki kandungan nikotin yang terdeteksi dengan munculnya puncak pada waktu retensi 14,08 detik. Nikotin memiliki gugus atom yang mengandung atom oksigen dan nitrogen dalam bentuk $\mathrm{O}-\mathrm{H}, \mathrm{N}-\mathrm{H}, \mathrm{C}=\mathrm{O}$ yang teradsorpsi pada permukaan logam sehingga dapat menghambat laju korosi (Guo et al., 2017). Hal tersebut telah diperkuat dengan hasil FTIR ekstrak daun tembakau pada Gambar
3 yang menunjukkan bahwa bahwa pada area $1636,04 \mathrm{~cm}^{-1}$ terdeteksi puncak yang menunjukkan gugus karbonil $\mathrm{C}=\mathrm{O}$ sedangkan pada area 3269,39 $\mathrm{cm}^{-1}$ terdeteksi puncak yang menunjukkan gugus NH/OH. Gugus atom tersebut berperan sebagai donor elektron pada permukaan logam yang berikatan dengan molekul inhibitor sehingga menyebabkan peningkatan densitas elektron. Peningkatan densitas elektron menyebabkan terjadinya inhibisi korosi (Mahgoub et al., 2011). 


\section{Pemanfaatan Ekstrak Daun Tembakau sebagai Inhibitor Korosi pada Logam Baja Karbon dan} Aluminium

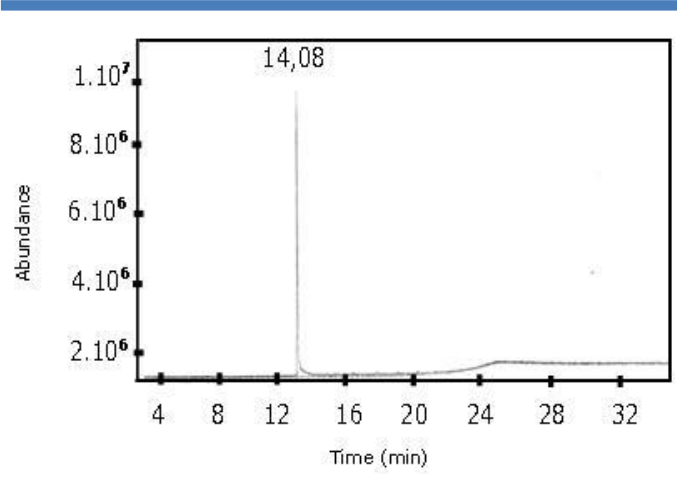

Gambar 2. Kromatografi Ekstrak Daun Tembakau

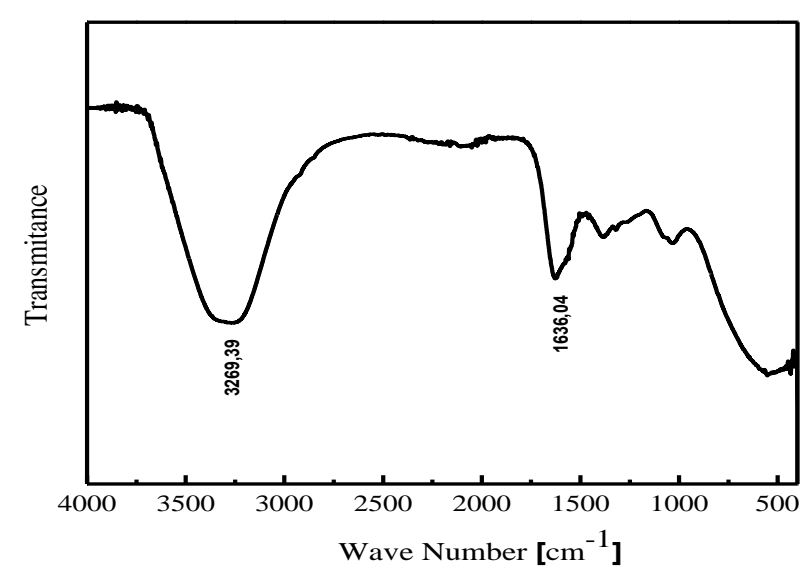

Gambar 3. FTIR Ekstrak Daun Tembakau
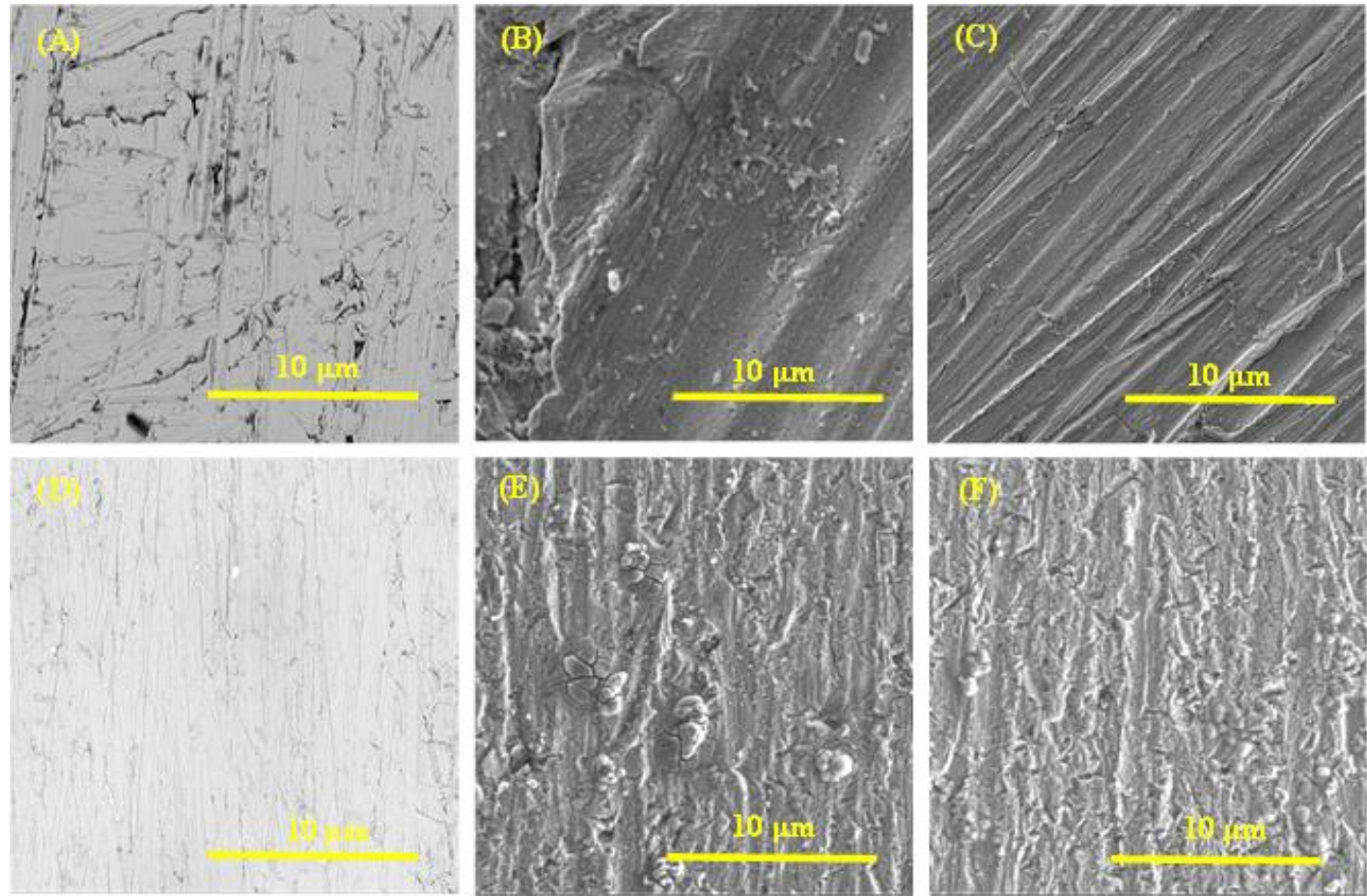

Gambar 4. SEM Permukaan Logam Besi (atas) dan Aluminium (bawah): A dan D Sebelum Kontak $\mathrm{HCl}$, B dan E Dengan Inhibitor $100 \mathrm{mg} / \mathrm{L}, \mathrm{C}$ dan D Dengan Inhibitor $700 \mathrm{mg} / \mathrm{L}$

Gambar 4 menunjukkan morfologi permukaan logam baja karbon dan aluminium sebelum dan setelah dikontakkan dengan larutan $\mathrm{HCl} 0,1 \mathrm{M}$. Hasil penelitian menunjukkan bahwa permukaan baja dan alumunium sebelum terkontak dengan larutan $\mathrm{HCl} \quad 0,1 \mathrm{M}$ cenderung smooth. Kontak dengan larutan $\mathrm{HCl}$ menyebabkan terjadinya degradasi pada permukaan logam akibat korosi.
Namun, tingkat degradasi atau kerusakan dari permukaan logam semakin rendah pada saat konsentrasi inhibitor ekstrak daun tembakau ditingkatkan. Hal tersebut membuktikan bahwa adsorpsi inhibitor ekstrak daun tembakau pada permukaan logam dapat membentuk protective barrier yang mampu menghambat korosi pada logam. Selain itu, hasil analisis laju korosi sebagaimana pada Tabel 1 menunjukkan 
bahwa secara umum laju korosi aluminium lebih rendah dibandingkan dengan laju korosi pada baja karbon pada konsentrasi inhibitor yang sama. Hal ini dapat disebabkan harga konstanta adsorpsi pada logam aluminium lebih besar dibandingkan dengan logam baja. Harga energi bebas pada adsorpsi inhibitor pada aluminium lebih negatif daripada baja sehingga tingkat adsorpsi logam aluminium terhadap inhibitor lebih besar dibandingkan dengan logam baja (Ezeokonkwo et al., 2012). Pernyataan tersebut didukung hasil perhitungan surface coverage yang secara umum menunjukkan bahwa pada konsentrasi inhibitor yang sama nilai fraksi surface coverage (permukaan yang tertutup inhibitor) logam aluminium lebih tinggi dibandingkan dengan logam baja karbon.

\section{KESIMPULAN}

Ekstrak daun tembakau dapat dimanfaatkan sebagai green corrosion inhibitor karena terbukti cukup efektif menurunkan laju korosi logam baja karbon dan aluminium di dalam larutan $\mathrm{HCl} 0,1$ M. Hasil pengujian polarisasi linear menunjukkan bahwa meningkatkan konsentrasi inhibitor ekstrak daun tembakau dapat menurunkan rapat arus korosi sehingga menyebabkan penurunan laju korosi pada baja karbon maupun aluminium. Peningkatan konsentrasi inhibitor ekstrak daun tembakau di dalam larutan $\mathrm{HCl}$ 0,1 $\mathrm{M}$ dapat menyebabkan peningkatan efisiensi inhibisi korosi pada logam baja maupun aluminium. Efisiensi inhibisi korosi tertinggi diperoleh pada konsentrasi inhibitor $700 \mathrm{mg} / \mathrm{L}$ yaitu sebesar $71,71 \%$ pada logam baja karbon dan $72,44 \%$ pada logam aluminium. Hasil pengujian SEM menunjukkan bahwa peningkatan konsentrasi inhibitor menyebabkan tingkat proteksi logam terhadap korosi semakin tinggi sehingga degradasi atau kerusakan permukaan logam akibat kontak dengan larutan $\mathrm{HCl}$ semakin rendah.

\section{DAFTAR RUJUKAN}

Ahmadi, R. N., Oediyani, S., \& Priyotomo, G. (2016). Pengaruh Penambahan Inhibitor Ekstrak Tembakau Terhadap Laju Koosi Internal Pipa Baja Api 5L X-52Pada Artificial Brine Water Dengan Injeksi Gas $\mathrm{CO}_{2}$. Jurnal Furnace, 2(1), 1-8.

Al-Otaibi, M. S., Al-Mayouf, A. M., Khan, M., Mousa, A. A., Al-Mazroa, S. A., \& Alkhathlan, H. Z. (2014). Corrosion Inhibitory Action of Some Plant Extracts on The Corrosion Of Mild Steel in Acidic Media. Arabian Journal of Chemistry, 7, 340-346.

Al-Turkustani, A. M. (2010). Aloe Plant Extract as Environmentally Friendly Inhibitor on The Corrosion of Aluminum in Hydrochloric Acid in Absence and Presence of Iodide Ions. Modern Applied Science, 4, 105-124.

Bhaskaran, R., Palaniswamy, N., Rengaswamy, N.S., \& Jayachandran, M., (2005). A Review of Differing Approaches Used to Estimate The Cost Of Corrosion (and Their Relevance in The Development of Modern Corrosion Prevention And Control Strategies). Anti-Corrosion Methods and Materials, 52, 29-41.

Bhawsar, J., Jain, P. K., \& Jain, P. (2015). Experimental and Computational Studies of Nicotiana Tabacum Leaves Extract as Green Corrosion Inhibitor for Mild Steel in Acidic Medium. Alexandria Engineering Journal, 54, 769-775. 
Chaubey, N., Singh, V. K., \& Quraishi, M. A. (2016). Papaya Peel Extract As Potential Corrosion Inhibitor For Aluminium Alloy In $1 \mathrm{M} \mathrm{Hcl}$ : Electrochemical And Quantum Chemical Study. Ain Shams Engineering Journal, Article In Press.

Chebouat, E., Dadamoussa, B., Gherraf, N., Gouamid, M., Allaoui, M., Cheriti, A., \& Khiari, A. (2013). Inhibition of Mild Steel Corrosion in $1 \mathrm{~N} \mathrm{HCl}$ Medium by Acid Extract of Ephedra Alata. International Journal of Electrochemichal Science, 8, 1214712153.

De-Souza, F. S. \& Spinelli, A. (2009). Caffeic Acid as a Green Corrosion Inhibitor For Mild Steel. Corrosion Science, 51, 642-649.

Ezeokonkwo, M. A., Ukoha, P. O., \& Nnaji, N. J. N. (2012). Green Inhibitor for Aluminium and Mild Steel in Acidic Media : A Case Study of Exudates of Eucalyptus Citriodora. International. J. Chemical Science, 10, 1365-1373.

Guo, L., Zhu, S. H., Zhang, S. T., He, Q., \& Li, W. H. (2014). Theoretical Studies of Three Triazole Derivatives as Corrosion Inhibitors for Mild Steel in Acidic Medium. Corrosion Science, 87, 366-375.

Hegazy, M., Abdallah, M., Alfakeer, M., \& Ahmed, H. (2018). Corrosion Inhibition Performance of a Novel Cationic Surfactant for Protection of Carbon Steel Pipeline in Acidic Media. International Journal of Electrochemichal Science, 13, 68246842.

Li, X., Chen, G., \& Zhu, H. (2016). Quantitative Risk Analysis on Leakage Failure of Submarine Oil and Gas Pipelines Using Bayesian
Network. Process Safety and Enviromental Protection, 103, 163173.

Liao, L. L., Mo, S., Luo, H. Q., \& Li, N. B. (2018). Corrosion Protection for Mild Steel by Extract from The Waste of Lychee Fruit in $\mathrm{HCl}$ Solution: Experimental and Theoretical Studies. Journal of Colloid and Interface Science, 520, 41-49.

Mahgoub, F. M., Al-Nowaiser, F. M., AlSudairi, A. M. (2011). Effect of Temperature on The Inhibition of The Acid Corrosion of Steel by Benzimidazole Derivatives. Protection of Metals and Physical Chemistry of Surfaces, 47, 381-394.

Mehdipour, M., Ramezanzadeh, B., \& Arman, S. Y. (2015). Electrochemical Noise Investigation of Aloe Plant Extract as Green Inhibitor on The Corrosion of Stainless Steel in $1 \mathrm{M}$ $\mathrm{H}_{2} \mathrm{SO}_{4}$. J. of Industrial and Engineering Chemistry, 21, 318-327.

M'hiri, N., Renaux, D. V., Rocca, E., Ioannou, I, Boudhrioua, N.M., \& Ghoul, M. (2016). Corrosion Inhibition of Carbon Steel in Acidic Medium by Orange Peel Extract and Its Main Antioxidant Compounds. Corrosion Science, 102, 55-62.

Mourya, P., Banerjee, S., \& Singh, M. M. Corrosion Inhibition of Mild Steel in Acidic Solution by Tagetes Erecta (Marigold Flower) Extract as a Green Inhibitor. Corrosion Science, 85, 352363.

Odewunmi, N. A., Umoren, S. A., \& Gasem, Z.M. (2015). Watermelon Waste Products as Green Corrosion Inhibitors For Mild Steel in $\mathrm{HCl}$ Solution. Journal of Environmental Chemical Engineering, 3, 286-296. 
Paramartha, D., Lazuardi, Y., \& Sumantri, I., (2013). Pemanfaatan Nikotin Pada Daun Tembakau Untuk Memproduksi Bioinsektisida Dengan Proses Ekstraksi Cair-Cair. Jurnal Teknologi Kimia dan Industri, 2, 233-239.

Qiang, Y., Zhang, S., Tan, B., \& Chen, S. (2018). Evaluation of Ginkgo Leaf Extract as an Eco-Friendly Corrosion Inhibitor of X70 Steel in $\mathrm{HCl}$ Solution. Corrosion Science, 133, 6-16

Setiawan, A., Novitrie, N. A., \& Ashari, L., (2017). Analisis Korosi Logam Tembaga dan Aluminium pada Biodiesel yang Disintesis dari Minyak Goreng Bekas. Seminar MASTER, tanggal 21 Nopember 2017. Surabaya: Politeknik Perkapalan Negeri Surabaya.

Verma, C., Ebenso, E. E., \& Quraishi, M. A. (2017). Corrosion Inhibitors for Ferrous and Non-Ferrous Metals and Alloys in Ionic Sodium Chloride Solutions: A Review. Journal of Molecular Liquids, 248, 927-942.

Yanuar, A. P., Pratikno, H., \& Titah, H. S. (2016). Pengaruh Penambahan Inhibitor Alami terhadap Laju korosi pada Material Pipa dalam Larutan Air Laut Buatan. Jurnal Teknik ITS, 5(2), G297-G302.

Yaro, A. S., Khadom, A. A., \& Wael, R. K. (2013). Apricot Juice as Green Corrosion Inhibitor of Mild Steel in Phosphoric Acid. Alexandria Engineering Journal, 52, 129-135. 